Article

\title{
Charge Transport in LDPE Nanocomposites Part I-Experimental Approach
}

\author{
Anh T. Hoang ${ }^{1}$, Love Pallon ${ }^{2}$, Dongming Liu ${ }^{2}$, Yuriy V. Serdyuk ${ }^{1}$, Stanislaw M. Gubanski ${ }^{1, *}$ \\ and Ulf W. Gedde ${ }^{2}$ \\ 1 Division of High Voltage Engineering, Department of Materials and Manufacturing Technology, \\ Chalmers University of Technology, Gothenburg SE-412 96, Sweden; anh.hoang@chalmers.se (A.T.H.); \\ yuriy.serdyuk@chalmers.se (Y.V.S.) \\ 2 Fiber and Polymer Technology, School of Chemical Science and Engineering, \\ KTH Royal Institute of Technology, Stockholm SE-100 44, Sweden; lovep@kth.se (L.P.); \\ donliu@kth.se (D.L.); gedde@kth.se (U.W.G.) \\ * Correspondence: stanislaw.gubanski@chalmers.se; Tel.: +46-31-772-1616
}

Academic Editor: Frank Wiesbrock

Received: 28 January 2016; Accepted: 9 March 2016; Published: 16 March 2016

\begin{abstract}
This work presents results of bulk conductivity and surface potential decay measurements on low-density polyethylene and its nanocomposites filled with uncoated $\mathrm{MgO}$ and $\mathrm{Al}_{2} \mathrm{O}_{3}$, with the aim to highlight the effect of the nanofillers on charge transport processes. Material samples at various filler contents, up to $9 \mathrm{wt} \%$, were prepared in the form of thin films. The performed measurements show a significant impact of the nanofillers on reduction of material's direct current (dc) conductivity. The investigations thus focused on the nanocomposites having the lowest dc conductivity. Various mechanisms of charge generation and transport in solids, including space charge limited current, Poole-Frenkel effect and Schottky injection, were utilized for examining the experimental results. The mobilities of charge carriers were deduced from the measured surface potential decay characteristics and were found to be at least two times lower for the nanocomposites. The temperature dependencies of the mobilities were compared for different materials.
\end{abstract}

Keywords: low-density polyethylene; nanocomposites; dc conductivity; charge carrier mobility; charge transport; trap depth

\section{Introduction}

Polyethylene (PE) has been widely used as cable insulation material thanks to its low electrical conductivity. Despite the successful application of this material for high voltage alternating current (HVAC) cables, a number of challenges has been encountered in its use in high voltage direct current (HVDC) counterparts [1]. Unlike the case of ac stress, the electric field distribution under dc stress is governed by material's dc conductivity. This parameter is dependent on both electric field and temperature. As cable insulation usually operates at a temperature gradient, electric field distribution inside the insulation bulk is a complex function of material properties and radial position [2]. Space charge accumulation and, hence, local field enhancements are usually observed inside HVDC insulation, which may stimulate accelerated ageing process [3].

The forecasted growth in worldwide demand for electrical power energy and the requirement of longer transmission distances are the incentives for designing extruded HVDC cables that should reliably work at high rated voltage, e.g., up to 1 megavolt (MV), and have high power transmission capability, up to several gigawatts (GW). For such HVDC cables, the problem of field enhancement and space charge accumulation must be effectively solved and the most important requirement should be an extremely low dc conductivity of its insulation. A promising approach for dealing with this task 
is the application of nanotechnology, which allows for creating new materials with superior properties by adding a small amount of nanoparticles [4]. In case of insulation for HVDC cables, even though the semi-crystallized PE can be considered itself as a natural nanometric dielectric [5], the introduction of nanoparticles brings about a variety of advantages. In particular, significant reduction in dc conductivity, negligible space charge accumulation in the bulk as well as an increased dielectric strength have been observed in PE nanocomposites in comparison to unfilled counterpart [6-10]. The improvements in properties of nanomaterials have been attributed to the formation of interfacial regions between nanofillers and base polymer which are characterized by enormously high ratio of surface area to volume [6,11].

Although many investigations on PE nanocomposites have been reported recently, the transport of charge carriers contributing to their dc conductivity is not fully understood yet. In this context, a model describing transport of charge carriers in PE with and without nanofillers is highly desirable for analyzing the role of nanofillers in conduction processes. To formulate such a model, consistent input parameters need to be provided, in particular, mobilities of charge carriers in the materials. The latter have been studied extensively for pure PE for which it has been found to be dependent on both electric field and temperature [12-15], while information is very limited in case of PE-based nanocomposites.

In the present investigation, we attempt to address several aspects in the above defined gap of knowledge. Both experimental and simulation techniques are utilized and the obtained results are reported in two articles. In the first one here, we present measured charging currents and surface potential decay (SPD) characteristics obtained at various temperatures on two types of low-density polyethylene (LDPE) nanocomposites as well as on unfilled material. The most important parameters governing the conduction processes in the materials are deduced, namely the mobilities of charge carriers and energy distributions of traps. In the second paper, a model of charge transport is developed for LDPE with and without nanofillers. Materials' parameters attained from the measured data are used as input for the model whereas the measured current characteristics are utilized for validation of the simulated results.

\section{Materials and Methods}

\subsection{Samples}

Nanocomposites were manufactured using two types of uncoated metal-oxide nanofillers, namely alumina $\left(\mathrm{Al}_{2} \mathrm{O}_{3}\right)$ and magnesia $(\mathrm{MgO})$. The $\mathrm{Al}_{2} \mathrm{O}_{3}$ particles had spherical shape with an average diameter of $40 \mathrm{~nm}$, whereas the $\mathrm{MgO}$ nanoparticles were in rounded hexagonal shape with an average size of $66 \mathrm{~nm}$ and a thickness of 10-20 nm. The nanoparticles used are characterized by narrow size distributions and high purity $[16,17]$. For preparing nanocomposites, a certain amount of nanoparticles and Irganox 1076 (used as antioxidant) were dispersed in heptane solvent and the suspension was added into LDPE powder. The obtained mixture was then shaken for $1 \mathrm{~h}$ and dried in an oven at $80^{\circ} \mathrm{C}$ to evaporate all the solvent. Finally, the dry mixture powder was compounded by thermal extrusion at $150{ }^{\circ} \mathrm{C}$ in $6 \mathrm{~min}$. The obtained materials were later on pressed to form $80 \mu \mathrm{m}$ thick films that have square shape with a side of $65 \mathrm{~mm}$. The prepared samples were then kept in a desiccator for preventing the intake of moisture from laboratory air.

To study the influence of filler content on material properties, two nanocomposites filled with $\mathrm{Al}_{2} \mathrm{O}_{3}$ at 1 and $3 \mathrm{wt} \%$ as well as five types of MgO-filled materials with filler content of $0.1,1,3,6$, and $9 \mathrm{wt} \%$ were prepared. All the materials contained the antioxidant at $0.02 \mathrm{wt} \%$ for avoiding degradation by oxidation. Both nanofillers are evenly distributed in LDPE matrix, as presented in [16] for $\mathrm{LDPE} / \mathrm{Al}_{2} \mathrm{O}_{3}$. In case of $\mathrm{LDPE} / \mathrm{MgO}$ at high filler contents (6 and $9 \mathrm{wt} \%$ ), clustered and agglomerated particles were observed. While the clusters only consist of a couple of nanoparticles and are less than a micrometer in cross-section, the agglomerates can be several micrometers large and built up of thousands of nanoparticles. Detailed information on the particle distance and the degree and size of agglomerates is presented in a separate publication [17]. 


\subsection{Conductivity Measurements}

Measurements of dc conductivity were carried out at applied electrical field of $\sim 30 \mathrm{kV} / \mathrm{mm}$. The test setup is shown in Figure 1. The dc test voltage was generated by a Glassman power supply (model FJ60R2) and the current was measured using an electrometer Keithley 6517A (Tektronix Inc., Beaverton, OR, USA). The experiments followed a standard procedure [18] by using a three-electrode system, of which the high voltage electrode was a stainless steel cylinder with a diameter of $45 \mathrm{~mm}$, the current measuring electrode was $30 \mathrm{~mm}$ in diameter, whereas the guard ring allowed for eliminating surface currents. A good contact of the high voltage electrode to the sample was provided by placing between them a layer of conducting silicon rubber (SIR) (Elastosil 570/70 from Wacker Chemie AG, Munich, Germany; dc conductivity of $28 \mathrm{~S} / \mathrm{m}$ ). The use of the SIR electrode in the measurements resembles the operating conditions of cable insulation that is always in contact with a semiconducting layer.

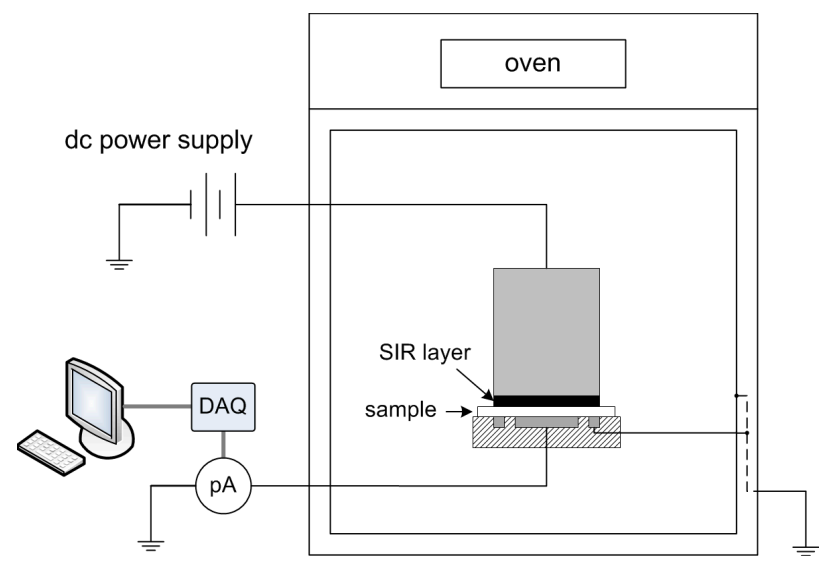

Figure 1. Schematic illustration of the test setup for conductivity measurements. DAQ, denotes data acquisition card and $\mathrm{pA}$, picoammeter.

The measurements were conducted at isothermal conditions (room temperature $\sim 20-22{ }^{\circ} \mathrm{C}, 40{ }^{\circ} \mathrm{C}$, and $60^{\circ} \mathrm{C}$ ). The latter two temperature levels were reached by placing the electrode system with inserted sample inside an oven. In this case, the metallic walls of the oven were grounded constituting a shielding box for avoiding electromagnetic disturbances. Thermal equilibrium at a predefined elevated temperature was attained by keeping the setup inside the oven for $\sim 2 \mathrm{~h}$ prior to each test. Thereafter, a dc voltage of $2.6 \mathrm{kV}$ was applied to the high voltage electrode for $4 \times 10^{4} \mathrm{~s}$ (i.e., $\sim 11 \mathrm{~h}$ ) and the current was recorded. Each test was repeated 2-3 times for checking the reproducibility of the results. The measured data were collected and stored in a personal computer via a data acquisition card (DAQ).

\subsection{SPD Measurements}

The experimental setup for SPD measurements is schematically illustrated in Figure 2. During the experiment one side of the film samples remains in contact with a grounded copper plate, while the other side is initially exposed to corona charging in air for $10 \mathrm{~s}$. The corona is generated in a triode electrode system [19], which consists of a needle and a grid electrodes connected to dc voltage sources. The use of the grid electrode allows for improving uniformity of the deposited charges as well as for controlling the level of surface potential on the charged surface. The magnitude of the voltage applied to the grid was selected so that the initial electric field induced in the samples by the deposited charges was close to the electric field applied during the conductivity measurements. The potential induced by deposited surface charges was measured by means of a non-contact technique [20] using a Kelvin probe placed above the sample surface. The probe was connected to an electrostatic voltmeter (Trek 
model 347B). The positions of the corona triode and the probe were controlled by a positioning system. Surface potential was continuously monitored at the center of the sample and potential distribution was regularly checked by scanning the surface through the center position. The data were stored for further analyses by using LabVIEW software (National Instruments, Austin, TX, USA).
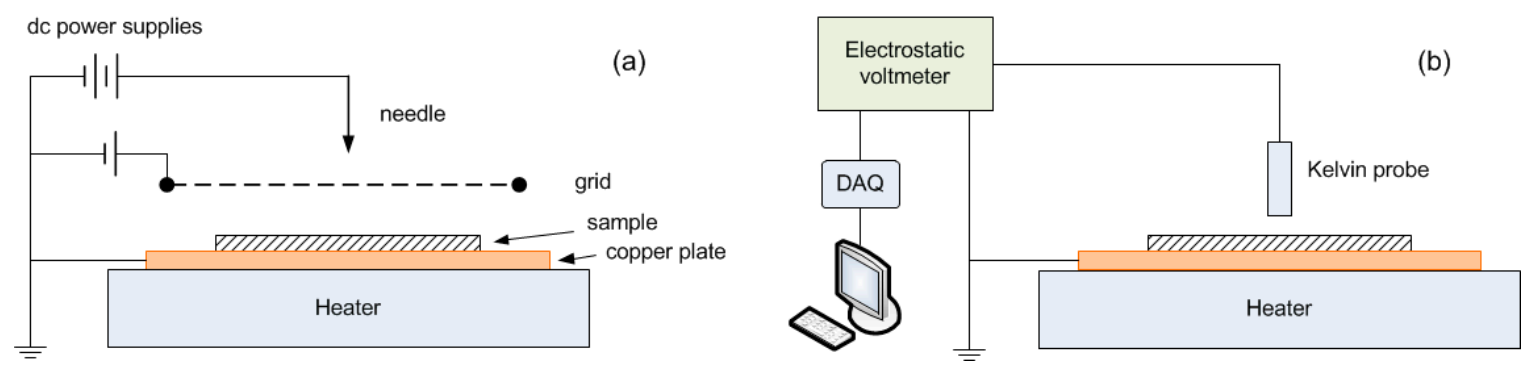

Figure 2. Schematic illustration of the setup for corona charging (a); and surface potential decay measurements (b).

The SPD measurements were conducted for two nanocomposites filled with 3 wt \% of nanoparticles as well as on the reference material at three temperatures, as for the conductivity measurements. The sample heating was realized by means of a hot plate on which the grounded copper plate rested. Prior to each test at elevated temperatures, the sample was preconditioned at a targeted temperature for $\sim 4 \mathrm{~h}$, thus assuring that homogeneous temperature distribution is achieved in the tested thin film.

The SPD measurements were also conducted on multilayered sample structures. For this, three specimen configurations were used $(\mathrm{NC} / \mathrm{NC}, \operatorname{Ref} / \mathrm{NC}(\mathrm{G}), \mathrm{NC} / \operatorname{Ref}(\mathrm{G}))$, as illustrated in Figure 3. The initial electric field induced inside the insulation was kept at the same level as for the measurements on single-layered samples by increasing the voltage applied to the grid electrode. Since surface potential exceeding $3 \mathrm{kV}$ should be detected, a Trek electrostatic voltmeter model $341 \mathrm{~B}$ was utilized which allowed for measurements up to $20 \mathrm{kV}$. The tests were conducted at room temperature only by following the same experimental procedure as described earlier. Each SPD measurement was performed 2-3 times for checking the repeatability of the results.

(a) NC/NC

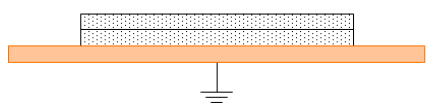

(b) $\operatorname{Ref} / \mathrm{NC}(\mathrm{G})$

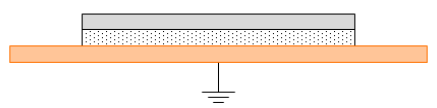

(c) NC/Ref(G)

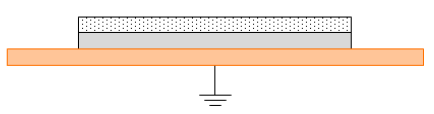

Figure 3. Multilayered sample structures used in SPD measurements: (a) NC/NC; (b) Ref/NC(G); and (c) NC/Ref(G). Ref and NC denote respectively the reference LDPE and LDPE $/ \mathrm{Al}_{2} \mathrm{O}_{3} 3 \mathrm{wt} \%$ nanocomposite whereas index $(\mathrm{G})$ indicates the layer in contact with the grounded copper plate during the test.

\section{Results and Discussion}

\subsection{Material DC Conductivity}

Preliminary measurements showed that the addition of a small amount $(0.02 \mathrm{wt} \%)$ of antioxidant into LDPE did not cause noticeable variation in material dc conductivity. LDPE doped with antioxidant is therefore utilized as a reference material throughout this study.

Figure 4 illustrates time variations of the density of the measured currents at $60^{\circ} \mathrm{C}$, which can be represented by power functions with various values of factor $n$

$$
j(t) \propto t^{-n}
$$



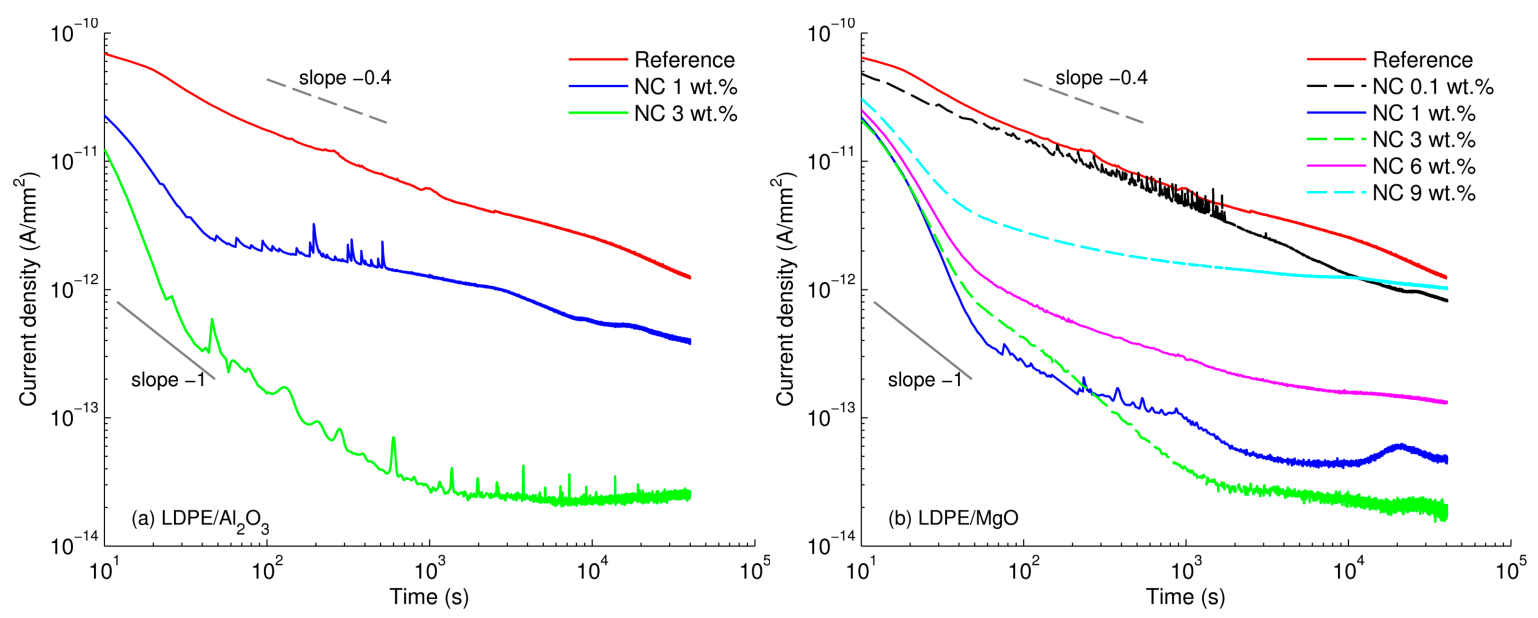

Figure 4. Densities of charging currents as functions of time measured at $60{ }^{\circ} \mathrm{C}$ for reference LDPE and both nanocomposites $\left(\mathrm{Al}_{2} \mathrm{O}_{3}(\mathbf{a})\right.$ and $\left.\mathrm{MgO}(\mathbf{b})\right)$.

As seen, the currents through the reference LDPE and LDPE/MgO $0.1 \mathrm{wt} \%$ materials decreased gradually and their time dependences exhibit a straight line (in the log-log scale) with a single slope $n \approx 0.4$. It is notable that these currents do not reach a steady state during the measuring time $(\sim 11 \mathrm{~h})$ used in the present study. Adamec and Calderwood [21] suggested that such slowly decaying currents can be attributed to the effect of space charge build-up in the bulk rather than to slow dipole orientation. Their hypothesis has been supported by the fact that the discharging current was remarkably lower than the charging counterpart, which indicated insignificant dipole depolarization [21]. Note that even though PE is well-known as a non-polar polymer, dipolar moieties such as impurities or by-products of oxidation may still exist in the material, resulting in the apparent polarization.

The shape of the recorded current traces changes significantly in cases of nanocomposites with filler content of $1 \mathrm{wt} \%$ or higher. A knee point at $~ 50-70 \mathrm{~s}$ after the voltage application can be seen in the characteristics of these materials. Within the initial 50-70 s, the current decayed rapidly with the slope $n$ exceeding 1 that is more likely due to the slow polarization as suggested in [21]. Thereafter, as the polarization process ceases, the conduction current becomes prevailing and the power factor $n$ in Equation (1) is getting closer to zero that corresponds to a steady state, i.e., dc conduction mode. In the following, the quasi-steady state conduction current observed at $\sim 4 \times 10^{4} \mathrm{~s}$ is used for comparisons. Overall, the measured currents are commonly lower for the nanocomposites as compared to the reference material, indicating a weakening of the charge transport. Thus, for LDPE $/ \mathrm{Al}_{2} \mathrm{O}_{3}$ nanocomposite at the nanofiller content of $3 \mathrm{wt} \%$ the current is reduced by almost two orders of magnitude. A less pronounced reduction is found in case of $1 \mathrm{wt} \%$ of nanofiller load. For LDPE/MgO nanocomposite, a significant drop is also exhibited at filler loading of $3 \mathrm{wt} \%$, whereas lower $(0.1 \mathrm{wt} \%)$ or higher $(9 \mathrm{wt} \%)$ amounts of this nanofiller do not result in a noticeable change of the property.

The materials' dc conductivities calculated by utilizing the charging currents at $4 \times 10^{4} \mathrm{~s}$ are shown in Figure 5. For LDPE, the outcome is in good agreement with data reported in literature, e.g., [8]. For the $\mathrm{LDPE} / \mathrm{Al}_{2} \mathrm{O}_{3}$ nanocomposite, the reduction in dc conductivity seems to be proportional to the filler content up to $3 \mathrm{wt} \%$. For the LDPE/MgO nanocomposite, a threshold-like behavior can be noticed at $\sim 3 \mathrm{wt} \%$. As seen from the plot, after reaching this point, further addition of nanoparticles causes a negative effect, i.e., the dc conductivity increases remarkably with higher filler loading that can be explained by a formation of agglomerations of nanoparticles in the base material [10]. The obtained results for the LDPE/MgO nanocomposite are in line with earlier reported investigations $[9,10]$ where a decrease in electrical conductivity in more than one order of magnitude and a threshold of filler loading at $\sim 2 \mathrm{wt} \%$ were observed. 


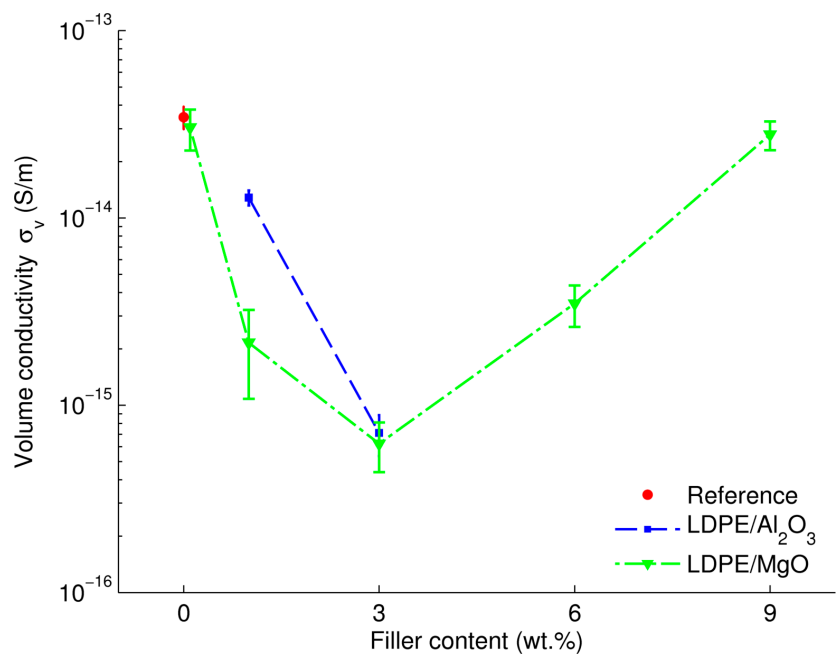

Figure 5. Dependence of dc conductivity (at $60^{\circ} \mathrm{C}$ ) of the studied nanocomposites on filler content.

Further investigations focused on analyzing the temperature dependence of dc conductivity. The study was carried out on the nanocomposites showing the greatest reduction in dc conductivity, i.e., the materials with filler loading of $3 \mathrm{wt} \%$. Since the results obtained for the two nanocomposites were quite similar, only the current densities measured for $\mathrm{LDPE} / \mathrm{Al}_{2} \mathrm{O}_{3}$ are presented in Figure 6 and are compared with those for unfilled LDPE. Results for LDPE/MgO nanocomposite can be found in Figure $\mathrm{S} 1$ of the supplementary materials. It is noteworthy to mention that the time dependence of the current density measured at room temperature on the reference LDPE was in good agreement with the corresponding result reported in [22]. As it is seen in Figure 6, the reduction in the current density associated with the introduction of nanofillers is the most remarkable at $60{ }^{\circ} \mathrm{C}$, whereas it is lower at room temperature.

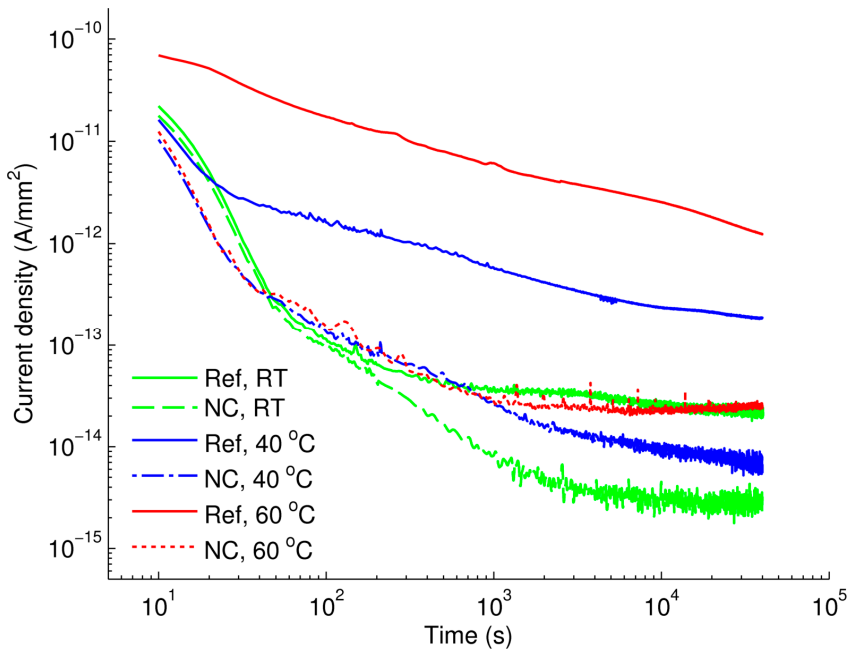

Figure 6. Densities of charging currents as functions of time measured at room temperature (RT) $\sim 20-22{ }^{\circ} \mathrm{C}, 40{ }^{\circ} \mathrm{C}$, and $60^{\circ} \mathrm{C}$ for the reference LDPE (Ref) and $3 \mathrm{wt} \% \mathrm{LDPE} / \mathrm{Al}_{2} \mathrm{O}_{3}$ nanocomposite (NC).

The current densities obtained at $4 \times 10^{4} \mathrm{~s}$ as functions of the reciprocal of the absolute temperature are shown in Figure 7. The activation energies $W_{\mathrm{a}}$ for the studied materials can be derived by assuming Arrhenius type of temperature dependence

$$
J_{C}(T)=J_{0} \exp \left(-\frac{W_{a}}{k T}\right)
$$


where $J_{C}(T)$ are measured current densities at various temperatures, $J_{0}$ is a constant value, $k$ is the Boltzmann constant, and $T$ is absolute temperature. The calculated values are indicated in the figure. The activation energy is higher for the reference LDPE as compared to both the nanocomposites. The outcome therefore suggests that at temperatures higher than $60^{\circ} \mathrm{C}$, the reduction in dc conductivity due to the introduced nanoparticles would be even more pronounced and the associated charge transport is much more suppressed.

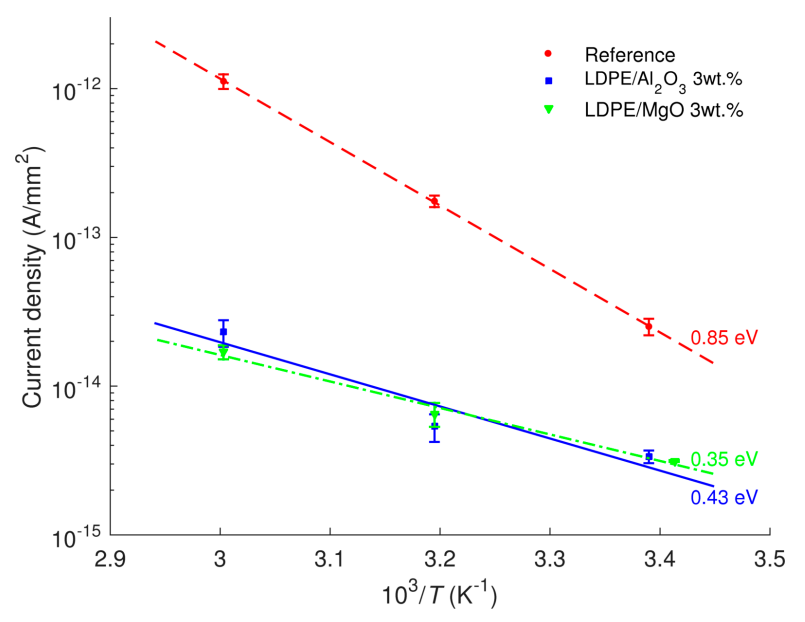

Figure 7. Temperature dependences of current densities at $4 \times 10^{4} \mathrm{~s}$ of LDPE and its nanocomposites. The calculated activation energies are indicated.

\subsection{SPD on Single-layered Insulation}

A distribution of surface potential measured on $\mathrm{LDPE} / \mathrm{Al}_{2} \mathrm{O}_{3}$ nanocomposite is illustrated in Figure 8 , which is typical results obtained at all considered temperatures on both materials. The initial surface potential distribution is relatively homogeneous in the center of the sample and the profile remains generally preserved during the measurements. A lateral spreading of the surface potential/charge is not noticed, indicating a negligible contribution of surface conduction to the decay process. As the Kelvin probe was always kept above the center of sample surface, zero electric field was maintained in the air gap between the surface center and the probe. Thus, neutralization by ionic species from air was to great extend prevented [23]. As a consequence, the decay is believed to be mainly caused by processes in the insulation bulk.

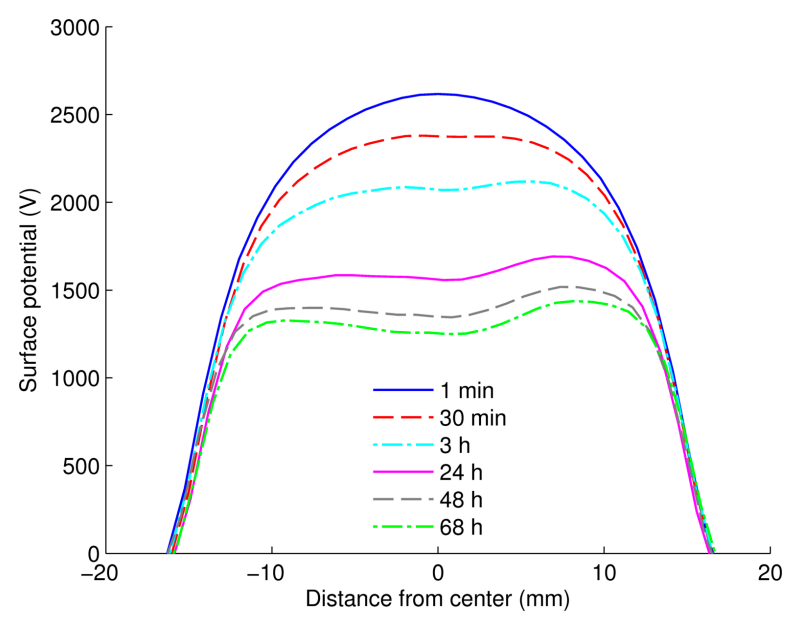

Figure 8. Distribution of surface potential during potential decay measurement on LDPE $/ \mathrm{Al}_{2} \mathrm{O}_{3} 3 \mathrm{wt} \%$ nanocomposite at $60^{\circ} \mathrm{C}$. 
The decays of surface potentials on $\mathrm{Al}_{2} \mathrm{O}_{3}$-nanofilled and reference LDPE are compared in Figure $9 \mathrm{a}$, where zero time corresponds to the end of corona charging. The initial potentials were recorded at $\sim 4-5 \mathrm{~s}$ afterwards and they are close to the value of grid potential, except for reference LDPE at $60^{\circ} \mathrm{C}$. The decay appears to be considerably slower for the nanofilled LDPE as compared to the reference LDPE, especially at higher temperatures. Since SPD is attributed to the conduction through the bulk, i.e., the transport of charge carriers within the material driven by the field of deposited surface charges, the experimental data imply significant limitation of charge transport due to the introduced nanoparticles.
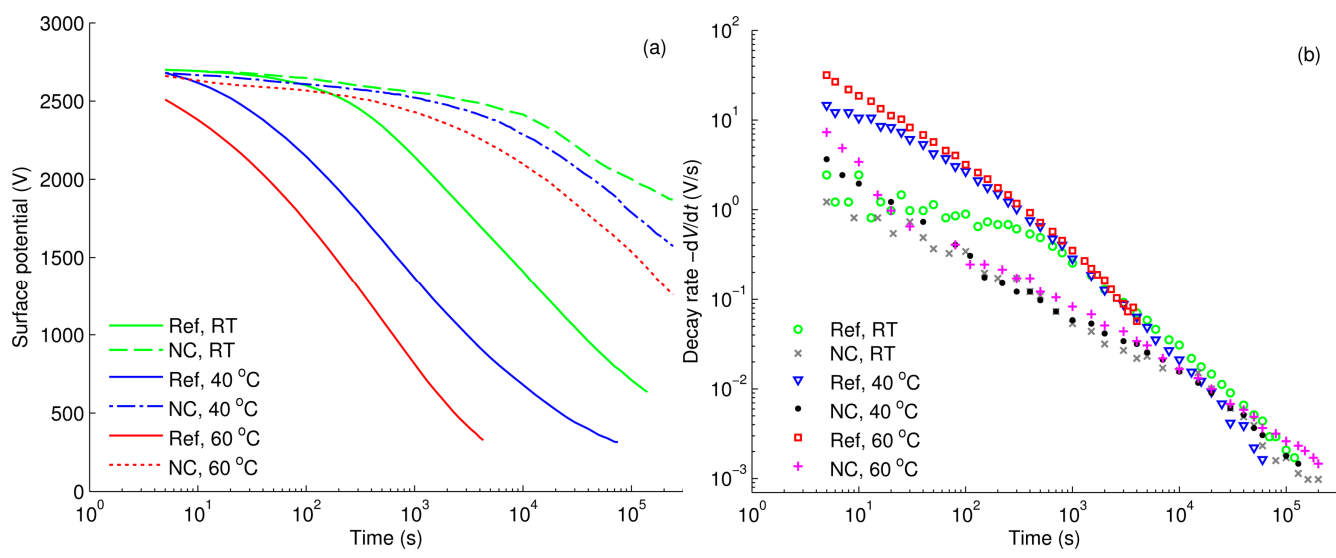

Figure 9. Measured surface potentials (a); and calculated decay rates (b) for reference LDPE (Ref) and LDPE $/ \mathrm{Al}_{2} \mathrm{O}_{3} 3 \mathrm{wt} \%$ nanocomposite (NC) at different temperatures.

The decay rates of the surface potentials (Figure 9b) can be represented as power-law functions of time. As temperature increases, a remarkable distinction in decay rates is observed at the initial stage, for the reference LDPE within the first $100 \mathrm{~s}$ of the decay. Note the initial drop of the potential was so high at $60^{\circ} \mathrm{C}$ that the first measured potential point was $\sim 200 \mathrm{~V}$ lower than the grid potential. However, after $10^{3} \mathrm{~s}$, the decay rates became similar for the samples exposed to different temperatures. This observation should not be misinterpreted as indicating a similarity in charge transport process. It is due to the difference in the magnitude of electric field induced in the material at certain time, in particular, the highest field strength presented in the sample subjected to the lowest temperature, so that the apparent decay rates are comparable. As the main features in the SPD characteristics are similar for both nanofilled LDPE, measured results on LDPE/MgO nanocomposite are presented in Figures S2,S3 in the supplementary materials.

\subsection{SPD on Multilayered Samples}

Measurements of surface potential decay on multilayered samples were conducted with the aim of revealing contributions of different processes to the decay in the considered conditions. Before presenting and discussing experimental results, we would like to provide a brief summary of physical processes that may take place during SPD measurements in the bulk and at interfaces of the flat samples depicted in Figures 2 and 3. First of all, high electric field induced by ionic charges created by corona and deposited on sample surface may stimulate charge generation processes in insulation bulk according to, for example, Poole-Frenkel mechanism. Secondly, electronic charges can be injected into the bulk from the metal-insulation interface [24]. Furthermore, other processes may occur at the air-insulation interface. A commonly used assumption is that deposited charges are trapped in deep surface traps and their release yields the decay of measured surface potential [25]. This surface controlled potential decay process is referred to as surface de-trapping mechanism. On the other hand, Baum et al. [26] suggested an electron transfer process between the deposited ionic charges and the surface states that results in the appearance of either holes or electrons in the latter, depending 
on the polarity of corona source. In other words, charges are apparently injected into insulation at the air-insulation interface. These injected charge carriers participate in the transport driven by the induced electric field that is reflected in the decaying surface potential. This hypothesis is commonly referred as the charge injection and transport model and has been used to explain results of SPD measurements in a variety of works, e.g. [13,14,27]. Even though an electric field exceeding $10^{7} \mathrm{~V} / \mathrm{m}$ may be considered as sufficient enough for charge injection, a threshold value corresponding to its onset is not clearly indicated in literature. It is noteworthy to mention that in general both the surface de-trapping and charge injection mechanisms may take place during SPD. The former seems to be dominating on thin dielectric layers of a few $\mu \mathrm{m}[25,28]$ in which extremely deep surface traps exist, whereas the latter is considered to be prevailing on relatively thicker samples, usually of a few tens of $\mu \mathrm{m}[13,14,26]$, provided that the induced field is strong enough.

Results of SPD measurements on multilayered samples are presented in Figure 10. They exhibit a resemblance in potentials measured within the first $200 \mathrm{~s}$. Thereafter, the fastest decay can be observed on Ref/NC(G) sample, whereas the slowest one-on NC/NC sample. If charge generation in the bulk, e.g., by Poole-Frenkel mechanism, is assumed to be the sole contributor to the decay, the same amount of electrons and/or holes would arise in conduction and/or valence bands due to excitation from donors and acceptors in samples Ref/NC(G) and NC/Ref(G). This eventually leads to similar potential decay on these specimens. As the latter is contradictory to the experimental results, this assumption can be ruled out. Combination of charge generation in the bulk and charge injection at the metal-insulation interface is also unlikely the dominating processes as this would lead to a faster decay on $\mathrm{NC} / \operatorname{Ref}(\mathrm{G})$ sample than on $\operatorname{Ref} / \mathrm{NC}(\mathrm{G})$.

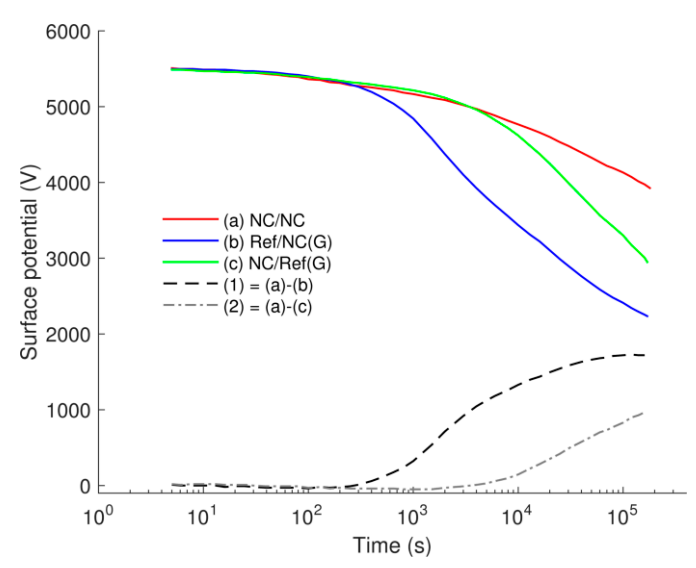

Figure 10. Surface potential decay on multilayered samples. Decay curves (a)-(c) are respectively obtained on samples (a)-(c) illustrated in Figure 3. Curve (1) is a difference in surface potential measured on samples (a) and (b), whereas curve (2) - is the difference for samples (a) and (c).

By comparing decay curves (a) and (c), one can observe that the reference LDPE as the bottom layer in NC/Ref(G) sample slightly alleviates the decay as compared to the NC bottom counterpart in $\mathrm{NC} / \mathrm{NC}$ sample. The difference in the decay is thus most likely due to an enhanced charge injection from the grounded copper plate into the LDPE layer. This can be related to the difference in dc conductivity measured on these materials. In contrast, significant difference in potential decays was obtained on samples NC/NC and Ref/NC(G) (the decay curves (a) and (b) in Figure 10). Since charges injected from the grounded copper plate were strongly prevented in both structures by the highly resistive NC bottom layer, the observed difference should mainly be attributed to the intensity of charge (hole) injection into the top layers of either NC or LDPE.

The possibility of injection at the air-insulation interface can be supported by appearance of return voltage [29] obtained in our experiments after short-circuiting the multilayered samples at the end of the SPD tests. The short-circuiting was done by placing a metallic electrode that was connected to 
ground on the sample surface for $10 \mathrm{~s}$. The return voltage is understood here as a potential build-up after temporarily short-circuiting the previously charged object. In the measurements, the return voltages were built up on all the three considered samples (Figure 11), but it was most considerable on Ref/NC(G) sample. According to a simplified model proposed in [30], the appearance of return voltage can be explained by movement of charge carriers back to the surface. A schematic distribution of charges on the surface and in the bulk of Ref/NC(G) sample is proposed in Figure 12. Holes that are initially injected into the top layer and transported in the bulk accumulate at the interface between reference LDPE and nanocomposite as well as in the insulation bulk (Figure 12a). The proposed charge distribution resembles the results of space charge measurements reported in [31]. It is thus postulated that the injection of electrons into the bottom layer is strongly impeded due to its low dc conductivity and presence of these electrons is not shown in the figure. After neutralization, ionic charges on insulation surface cease and the electric field within the top layer is mainly created by the hole space charges. This corresponding induced field should be strongly reduced as compared to that before neutralization and its direction is altered (Figure 12b). The charge transport driven by this weak field requires more time to reach equilibrium distribution inside the considered sample. As an illustration, the measured return voltage did not reach a steady state level even after $18 \mathrm{~h}$. Removal of the top LDPE layer led thereafter to an abrupt increase of the measured return voltage from $\sim 570 \mathrm{~V}$ to $\sim 660$ $\mathrm{V}$, as shown in the inset in Figure 11. This implies that the measured return voltage would increase further if the top layer was not removed. In contrast, the return voltage build-up for NC/NC sample was very small $(\sim 10 \mathrm{~V})$, which can be explained by the reduced charge transport in the nanocomposite. For NC/Ref(G), the return voltage was $\sim 100 \mathrm{~V}$, which is most likely associated with the transport of negative space charges in the bottom layer of LDPE.

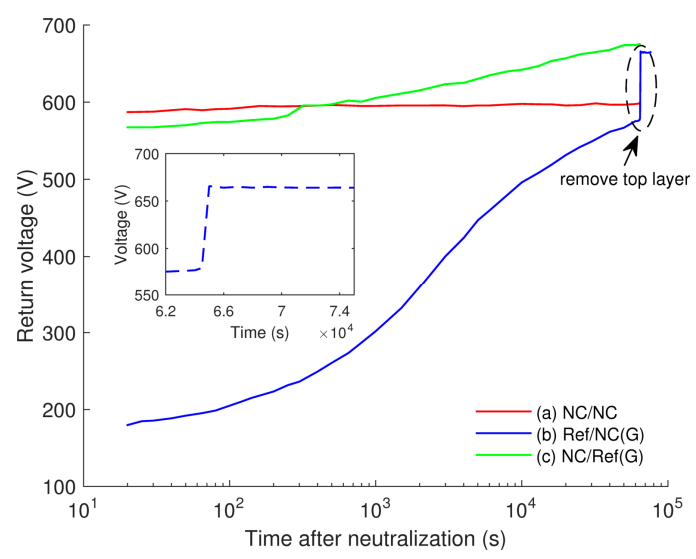

Figure 11. Return voltages measured after short-circuiting multilayered samples for $10 \mathrm{~s}$ at the end of SPD measurement. The inset shows the measured potential before and after removal of the top layer of sample Ref/NC(G).
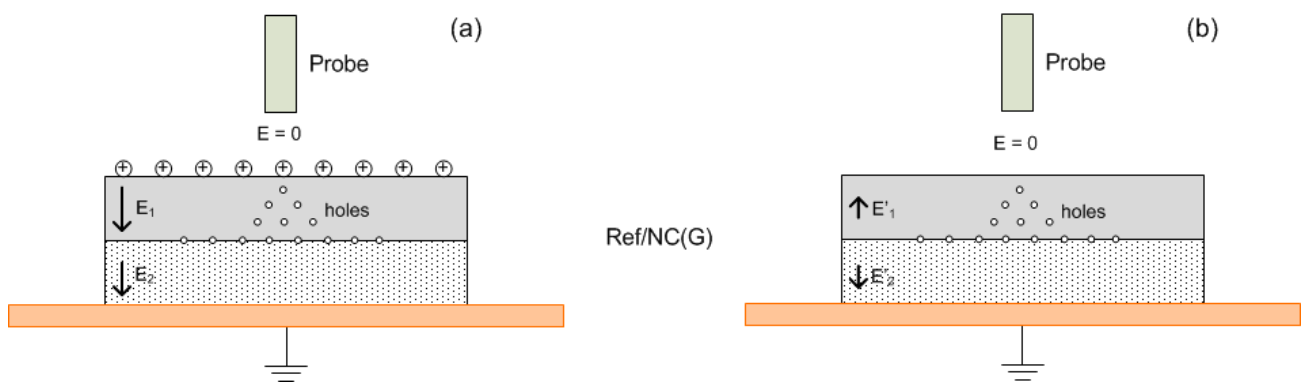

Figure 12. Schematic illustration of charge distribution and electric field (a) prior to; and (b) immediately after short-circuiting the Ref/NC(G) sample. 
By comparing the results of SPD measurements on samples Ref/NC(G) and NC/Ref(G), see decay curves (b) and (c) in Figure 10, one can claim that the contribution of injected positive charges to the decay outweighed by far that of the injected negative charges. The experimental results are also consistent with the hypothesis that positive holes dominate the charge transport in LDPE [32]. In complementary, it can be suggested that this feature is preserved in LDPE nanocomposites, even though the introduction of nanofillers strongly weakens the transport of both the injected holes and electrons.

An additional interesting outcome from the study is presented in Figure 13, where the decay rates of surface potential measured on single-layered reference LDPE sample and on multilayered Ref/NC(G) are compared. As can be seen, the results for both cases are very similar and show a knee point at $\sim 10^{3} \mathrm{~s}$, where the slope of the decay rate characteristic changes. The knee point can be attributed to the arrival of the charge carriers injected at the air-insulation interface [29] to the counter electrode or to the materials' interface. Consequently, the corresponding time $\sim 10^{3} \mathrm{~s}$ may be treated as a transit time of injected holes in the single-layered LDPE sample or that in the top layer of the Ref/NC(G) sample.

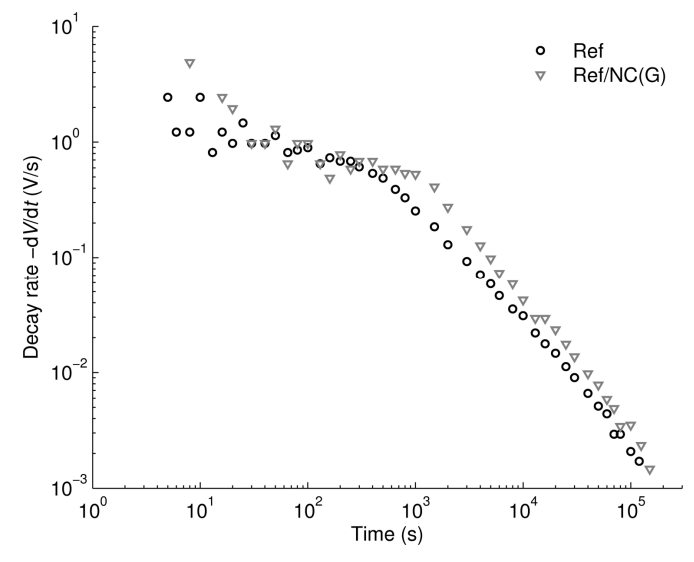

Figure 13. Decay rate of surface potential on reference LDPE and Ref/NC(G).

In summary, the results of SPD measurements on multilayered samples provide convincing evidence that bipolar charge injection takes place under the experimental conditions of this study, though the positive charge carriers (holes) dominate the transport in reference LDPE. This conclusion can also be extended to the case of single-layered sample, as a similar magnitude of the initial field strength is induced inside the material bulk.

\subsection{Mobility of Charge Carriers Deduced from SPD Measurements}

Dated back to the 60 and $70 \mathrm{~s}$ of the last century, the main interest of SPD measurements was related to explanation of the crossover phenomenon that was first reported by Ieda et al. [33]. The crossover phenomenon is referred to a faster decay process recorded on dielectric materials being charged to a higher surface potential, so that decay curves cross over each other if their initial surface potentials are different. The crossover phenomenon can be attributed to the non-linear behavior of the dielectric exposed to high electrical field. One of the models that provides a reasonable explanation for this was developed by Sonnonstine and Perlman in 1975 [27]. It accounts for injection of charge carriers from the air-insulation interface and their transport in the bulk of dielectric. By using the model, the authors derived effective mobility of charge carriers [34] which is proportional to the initial decay rate and inversely proportional to the square of the initial field:

$$
-\left(\frac{d V}{d t}\right)_{t=0}=\frac{\mu}{2}\left(\frac{V}{L}\right)_{t=0}^{2}
$$


Thus, this method can be applied to attain mobility of holes in reference LDPE where they are injected from the air-insulation interface and dominate in charge transport as discussed in Section 3.3 (the same seems to be also valid for the studied LDPE nanocomposites). An alternative way relies on the observation of the knee point in the decay rate characteristics, being attributed to the transit time of charges through the bulk [29]. However, since a knee point is only discernible for reference LDPE at room temperature (Figure 9b), this method is solely applicable in this particular case.

Values of the effective mobility of holes in LDPE at room temperature calculated by the two described methods are respectively $4.2 \times 10^{-15}$ and $2.4 \times 10^{-15} \mathrm{~m}^{2} /(\mathrm{Vs})$, which can already be considered as fairly agreeing with each other. The hole mobility in PE within a range $(1-5) \times 10^{-15}$ $\mathrm{m}^{2} /(\mathrm{Vs})$ at electrical field strength of $(2-4) \times 10^{7} \mathrm{~V} / \mathrm{m}$ was obtained in numerous investigations of surface charge decay $[13,14,26,35]$, space charge measurements [32] as well as measurements of transient current [36]. Either slightly lower [15] or marginally higher [34] values of mobility can also be found in literature. As for electron mobility, it has been reported to be few times up to one order of magnitude higher than for the holes [13,32].

The results obtained by the procedure proposed by Sonnonstine and Perlman are illustrated in Figure 14. As seen, the effective mobility of holes is lower for the nanocomposites, and this difference exaggerates at higher temperatures. The reduction in charge mobility in nanofilled materials has also been reported in $[7,10]$. Lewis [37] has recently explained the reduced mobility of charge carriers in nanocomposites by modifications introduced by nanoparticles to the energy structure of the amorphous phase in semi-crystalline PE. The author attributes the hole transitions in unfilled PE to tunneling between donor and acceptor sites in the interfacial regions of the amorphous phase [38]. Thereby, the presence of nanoparticles modifies the height of the energy barrier for tunneling as well as the tunneling distance. As a consequence, the time for hole transitions is lengthened and charge carrier mobility decreases [37].

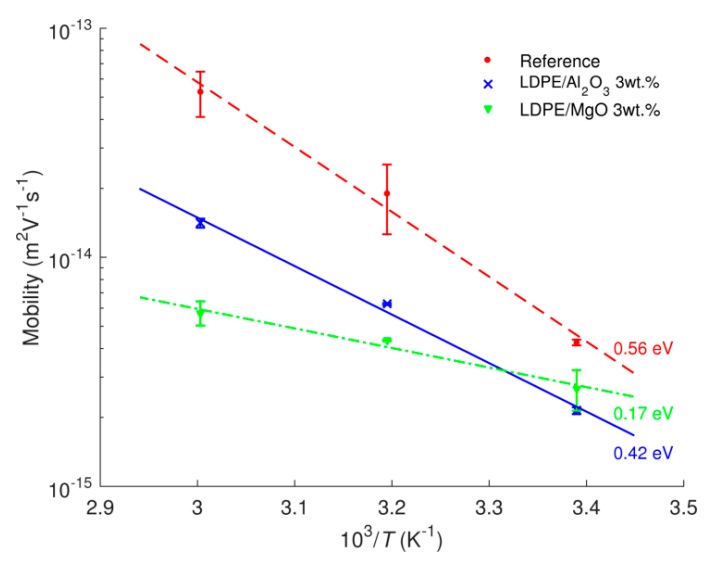

Figure 14. Temperature dependences of charge carrier (hole) mobility derived based on Sonnonstine and Perlman model.

The activation energy for carrier mobility $W_{a \mu}$ can be obtained by using Arrhenius dependence similar to Equation (2):

$$
\mu(T)=\mu_{0} \exp \left(-\frac{W_{a \mu}}{k T}\right)
$$

where $\mu(T)$ represents charge mobility at temperature $T$ and $\mu_{0}$ is a constant. The respective calculated activation energies are indicated in Figure 14 and provided Table 1. The latter also provides activation energies derived earlier from the dc conductivity measurements. It is noteworthy to observe that the values of activation energies for $\mathrm{LDPE} / \mathrm{Al}_{2} \mathrm{O}_{3}$ nanocomposite obtained by both methods are close 
to each other. However, this is not the case for reference LDPE and LDPE/MgO nanocomposite. By recalling the expression for the current density $j$

$$
j=q E \sum_{i} n_{i} \mu_{i}
$$

where $q$ is elementary charge $\left(q=1.6 \times 10^{-19} \mathrm{C}\right)$, it is suggested that for the latter two materials, the density $n_{i}$ of mobile charge carriers may also increase with temperature.

Table 1. Activation energies (in eV) of dc current density and carrier mobility for reference LDPE and its nanocomposites.

\begin{tabular}{ccc}
\hline Materials & Derived from Current Density & Derived from Charge Mobility \\
\hline $\mathrm{LDPE}$ & 0.85 & 0.56 \\
$\mathrm{LDPE} / \mathrm{Al}_{2} \mathrm{O}_{3} 3 \mathrm{wt} \%$ & 0.43 & 0.42 \\
$\mathrm{LDPE} / \mathrm{MgO} \mathrm{wt} \%$ & 0.35 & 0.17 \\
\hline
\end{tabular}

Conduction in PE has been discussed in a variety of works. A short summary provided in [39] shows that different conduction mechanisms may dominate in the material, depending on experimental conditions. Although the presented values of activation energy vary broadly, a range of $0.84-1.2 \mathrm{eV}$ appears commonly and the activation energy gained in this study is close to the lower limit of the indicated interval. On the other hand, not much information can be found on the activation energy level for conduction in PE nanocomposites. The lower values of activation energy for the nanofilled LDPE presented here indicate that the conduction processes are less temperature-dependent, which would lead to less pronounced field enhancement and space charge accumulation in HVDC cable insulation, which is a positive aspect brought about by the nanofillers.

\subsection{Plot of $-t d V / d t$ vs. $\log (t)$}

The plot of $-t \mathrm{~d} V / \mathrm{d} t$ vs. $\log (t)$ has been widely employed for representing data of SPD measurements as it may reveal information about charge trapping and transport in disordered solids. As pointed out in [28], for the case of exponential potential decay $V=V_{0} \exp (-t / \tau)$, the peak in this plot corresponds to the characteristic time $\tau$. The exponential potential decay is however rarely observed in reality. The peak of the curve $-t \mathrm{~d} V / \mathrm{d} t v s . \log (t)$ for a general decay shape can be related either to an average transit time of charge carriers, provided that charge injection takes place, or to an average residence time of charges in trapping sites in the case the surface de-trapping dominates [28]. The later hypothesis has been linked to the demarcation energy model [25], according to which the release of charges from traps at particular time $t$ yields potential decay $\mathrm{d} V / \mathrm{d} t$, and hence, the plot of $-t \mathrm{~d} V / \mathrm{d} t$ vs. $\log (t)$ shows a dynamic border between the filled (deeper) and the emptied (shallower) localized states. Thus, the energy depth of traps $E_{\mathrm{t}}$ is determined by time $t$ that charges spend in them:

$$
E_{t}=k T \ln \left(v_{0} t\right)
$$

where $v_{0}$ is the attempt-to-escape frequency. Since $-t \mathrm{~d} V / \mathrm{d} t$ is proportional to the trap density and time $t$ is related to the trap depth, the characteristic $-t \mathrm{~d} V / \mathrm{d} t v s$. $\log (t)$ provides the image of trap energy distribution in considered materials.

The plots of $-t \mathrm{~d} V / \mathrm{d} t$ vs. $\log (t)$ for reference LDPE obtained at different temperatures are presented in Figure 15a. At room temperature, the characteristic shows a broad peak with a shoulder. The time corresponding to the shoulder $\left(\sim 10^{3} \mathrm{~s}\right)$ is close to the transit time of charge carriers, whereas the peak time $\left(\sim 10^{4} \mathrm{~s}\right)$ is longer and appears to be the average dwelling time of charges in deep traps. As temperature rises, the peaks become narrower and the shoulder less pronounced. One can derive the value of the attempt-to-escape frequency $v_{0}$ by using the characteristics of $-t \mathrm{~d} V / \mathrm{d} t v s . \log (t)$ obtained at different temperatures with an assumption of temperature-invariant distribution of trap 
energy [25]. The calculation provides a value $v_{0} \approx 4 \times 10^{8} \mathrm{~s}^{-1}$ and the trap depth at maximum density is $E_{\mathrm{t}} \approx 0.72 \mathrm{eV}$ (Figure 15b). Both the derived values appear to be much lower than the commonly accepted parameters $\left(v_{0}\right.$ in order of $10^{12} \mathrm{~s}^{-1}$ and $\left.E_{t} \approx 1.0 \mathrm{eV}\right)$. This discrepancy might be attributed to the fact that the decay is controlled by more than a single mechanism. It should be noted that by using the same procedure [25] low levels of the attempt-to-escape frequency $\left(v_{0}=2 \times 10^{5} \mathrm{~s}^{-1}\right)$ and the trap depth $\left(E_{\mathrm{t}} \approx 0.36 \mathrm{eV}\right)$ have also been found for polypropylene [28].
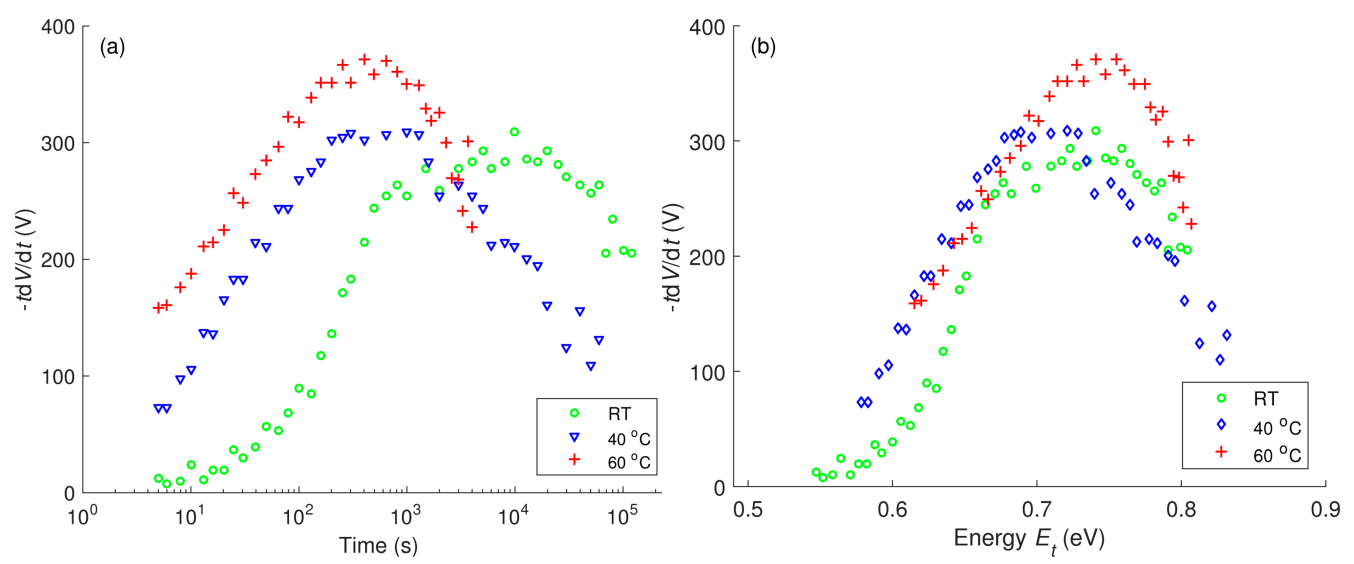

Figure 15. Plots $-t \mathrm{~d} V / \mathrm{d} t$ vs. $\log (t)(\mathbf{a})$; and $-t \mathrm{~d} V / \mathrm{d} t$ vs. $E_{t}(\mathbf{b})$ obtained at different temperatures for reference LDPE.

In Figure 16, the energy distributions of traps are compared for the reference LDPE and $\mathrm{LDPE} / \mathrm{Al}_{2} \mathrm{O}_{3}$ nanocomposite by assuming the attempt-to-escape frequency $v_{0} \approx 6 \times 10^{12} \mathrm{~s}^{-1}$. For the reference material, the distribution is characterized by a peak at $\sim 1 \mathrm{eV}$, which may be associated with trapping centra revealed by measurements of thermally stimulated currents (TSC) and attributed to physical defects in amorphous-crystalline interfaces and in crystalline region of PE [40]. For the nanofilled material, the image of trap distribution shifts to deeper trap energy. A shoulder is also found at $\sim 1 \mathrm{eV}$, suggesting an identical origin as in reference LDPE. In addition, the trap energy distribution of the nanocomposite implies a peak arising outside of the measurement window (at time exceeding $4.2 \times 10^{5} \mathrm{~s}$ ) that can be associated with a deeper trap level $\left(E_{\mathrm{t}}>1.1 \mathrm{eV}\right)$. The appearance of this trapping level is most likely caused by the presence of nanofillers in the material; in particular in the interfacial region between nanofiller particles and the polymer. The energy depth of the trap may be as high as $2 \mathrm{eV}$, as revealed by TSC measurements on LDPE/MgO nanocomposite [41].

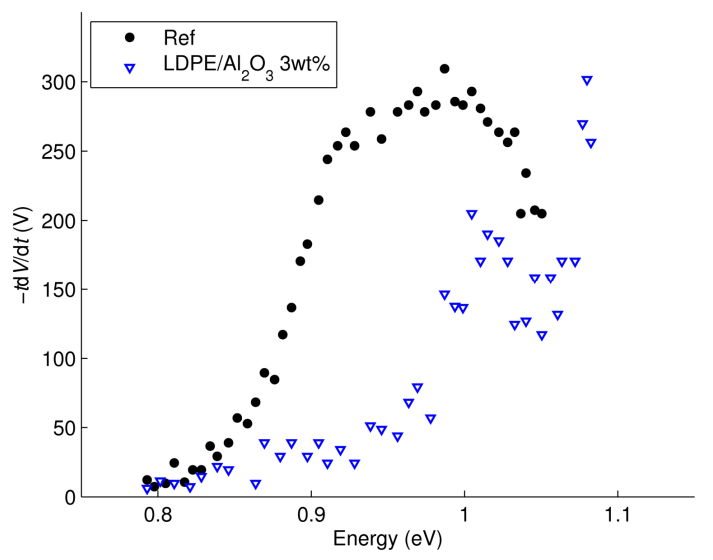

Figure 16. Trap energy distributions in reference LDPE and its nanocomposite. 


\subsection{Current Density Deduced from SPD Measurements}

During SPD measurement under open circuit configuration, the total current density in elementary volume of dielectric is zero

$$
j(x, t)+\frac{\partial(\varepsilon E(x, t))}{\partial t}=0
$$

where $j(x, t)$ is space- and time-dependent conduction current density and the second term represents displacement current, $\varepsilon$ being the real part of material permittivity, $E$ stands for electric field. The externally measurable conduction current density through the insulation can be defined as

$$
J(t)=\frac{1}{L} \int_{0}^{L} j(x, t) d x
$$

where $L$ is sample thickness. By substituting Equation (7) into Equation (8) and noting the flat response of $\varepsilon$ on frequency for LDPE and its nanocomposites [10], one obtains

$$
J(t)=-\frac{\varepsilon}{L} \int_{0}^{L} \frac{\partial E(x, t)}{\partial t} d x=-\frac{\varepsilon}{L} \frac{d V(t)}{d t}
$$

Equation (9) establishes a relationship between the conduction current density in SPD experiments and the decay rate of the measured potential. The current density is thus calculated and its dependence on electric field is examined in this section. Here the average magnitude of the electric field induced in the insulation $E=V / L$ is used.

A log-log plot of the current density versus electric field in reference LDPE presented in Figure 17a indicates that factor $m$ in the dependency $J \propto E^{m}$ decreases with temperature. Since $m>2$, the conduction current in reference LDPE is most likely governed by the space charge limited current (SCLC) mechanism for materials with traps, see Equation (10) [42], rather than the SCLC in trap-free materials described by the Mott-Gurney square law, see Equation (11) [43]:

$$
\begin{gathered}
J \propto \frac{V^{l+1}}{L^{2 l+1}} \\
J=\frac{9}{8} \varepsilon \mu \frac{V^{2}}{L^{3}}
\end{gathered}
$$

In Equation (10), factor $l=T_{C} / T$, where $T_{C}$ is the characteristic temperature of the proposed exponential distribution of trap density [42]. Further, Schottky and Poole-Frenkel plots for reference LDPE are illustrated in Figures 18a and 19a, respectively. As seen, the magnitudes of the relative permittivity used to get best fit (provided in the curves) are quite different from the value 2.3 commonly reported for PE. This fact indicates that neither Schottky injection mechanism nor Poole-Frenkel mechanism satisfactorily explain the behavior of the conduction current density $J$ at all considered temperatures. The change of the mechanism governing the conduction in LDPE with temperature has been noted in [44], where Schottky injection has been found to dominate at room temperature, but not at elevated ones.

The field dependencies of current density in LDPE $/ \mathrm{Al}_{2} \mathrm{O}_{3}$ nanocomposite are illustrated in Figures $17 \mathrm{~b}, 18 \mathrm{~b}$ and $19 \mathrm{~b}$, whereas the calculated results for LDPE/MgO nanocomposite are provided in supplementary materials (Figures S4-S6). The derived parameters $m$ and $\varepsilon_{\mathrm{r}}$ of these dependencies are provided in Table 2 for comparison. For both nanocomposites, the current density curves show a knee point at which the slopes change, and hence, the characteristics can be divided into two regions as indicated in the figures. It is noteworthy that the time corresponding to the observed knee point is close to the transit time calculated by using the hole mobility deduced in Section 3.4. Thus, the rapid decrease of current densities within the first region can be explained by a transient process 
followed the charge injection at the air-insulation surface. As the injected charges reach the counter electrode, the field dependence of current densities become less pronounced, as shown in the second region. Parameters $m$ and $\varepsilon_{\mathrm{r}}$ are thus calculated only in the latter region for avoiding the effect of the transient process at the initial stage. As seen, the power factor $m$ in the dependency $J \propto E^{m}$ is significantly higher for both nanocomposites as compared to that of reference LDPE. SCLC mechanism followed Equation (10) appears to be the dominating conduction mechanism in the nanocomposites. In contrast, both Schottky injection mechanism and Poole-Frenkel mechanism cannot fully explain the experimental data of the nanofilled materials under consideration. This topic therefore requires further investigation.
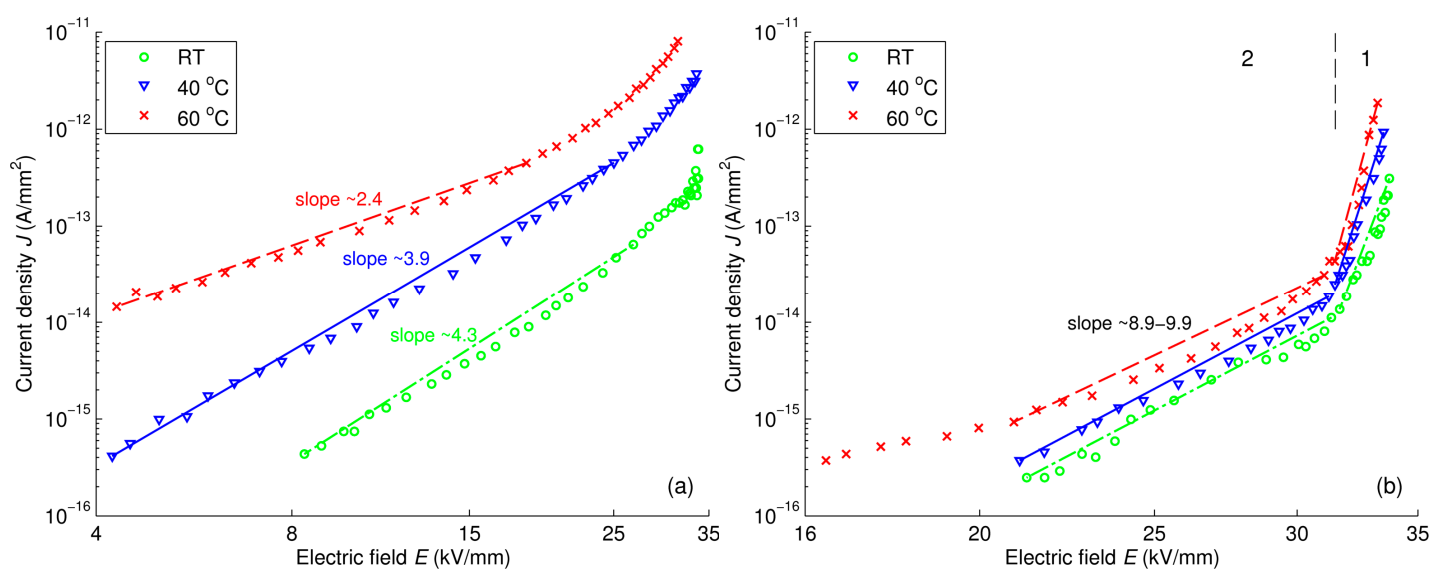

Figure 17. Log-log plot of $J$ vs. $E$ for reference LDPE (a); and LDPE $/ \mathrm{Al}_{2} \mathrm{O}_{3} 3$ wt $\%$ nanocomposite (b) at various temperatures. Regions 1 and 2 in figure (b) are featured by different slopes of the dependencies.
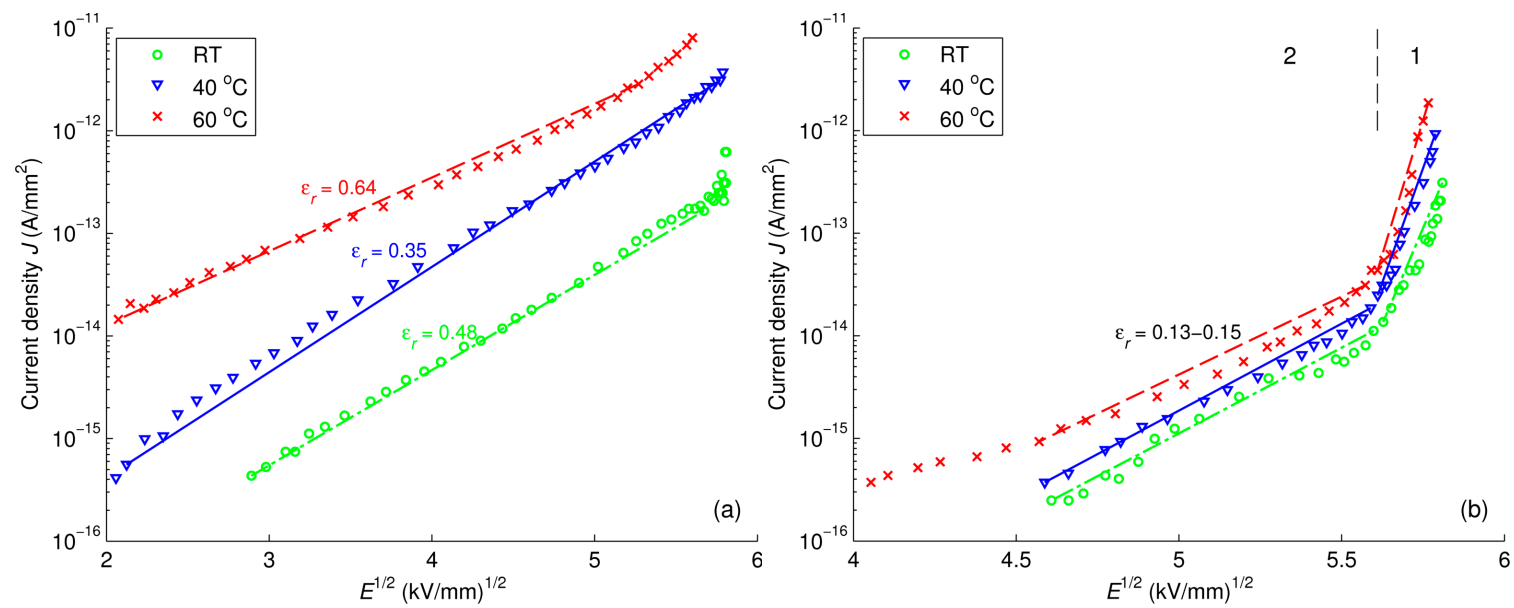

Figure 18. Schottky plot for reference LDPE (a); and $\mathrm{LDPE} / \mathrm{Al}_{2} \mathrm{O}_{3} 3 \mathrm{wt} \%$ nanocomposite (b) at various temperatures. Regions 1 and 2 in figure (b) are featured by different slopes of the dependencies.

Table 2. Calculated parameters in characteristics of $J$ vs. E. Note that the obtained values of $\varepsilon_{\mathrm{r}}$ below 1 do not have physical significance.

\begin{tabular}{ccccccccccc}
\hline \multirow{2}{*}{ Characteristics } & \multirow{3}{*}{ Calculated Parameters } & \multicolumn{3}{c}{ LDPE } & \multicolumn{4}{c}{ LDPE/Al $\mathbf{O}_{\mathbf{3}} \mathbf{N C}$} & \multicolumn{3}{c}{ LDPE/MgO NC } \\
\cline { 3 - 12 } & & $\mathbf{R T}$ & $\mathbf{4 0} \mathbf{C}$ & $\mathbf{6 0}{ }^{\circ} \mathbf{C}$ & $\mathbf{R T}$ & $\mathbf{4 0}{ }^{\circ} \mathbf{C}$ & $\mathbf{6 0}{ }^{\circ} \mathbf{C}$ & $\mathbf{R T}$ & $\mathbf{4 0}{ }^{\circ} \mathbf{C}$ & $\mathbf{6 0}{ }^{\circ} \mathbf{C}$ \\
\hline$J \propto E^{m}$ & $m$ & 4.3 & 3.9 & 2.4 & 9.8 & 9.9 & 8.9 & 11.5 & 9.6 & 5.6 \\
Schottky & $\varepsilon_{\mathrm{r}}$ & 0.48 & 0.35 & 0.64 & 0.15 & 0.13 & 0.14 & 0.12 & 0.14 & 0.30 \\
Poole-Frenkel & $\varepsilon_{\mathrm{r}}$ & 3.2 & 2.4 & 6.8 & 0.74 & 0.64 & 0.72 & 0.56 & 0.67 & 1.76 \\
\hline
\end{tabular}



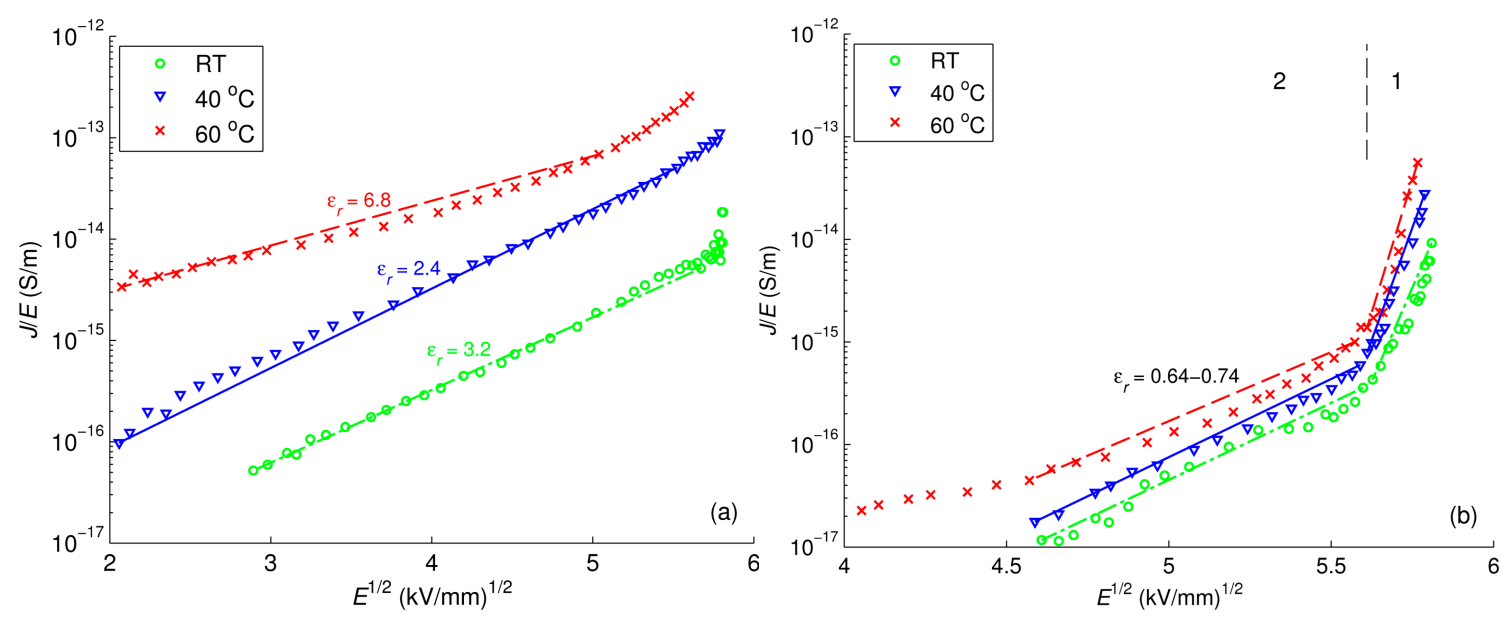

Figure 19. Poole-Frenkel plot for reference LDPE (a); and LDPE $/ \mathrm{Al}_{2} \mathrm{O}_{3} 3 \mathrm{wt} \%$ nanocomposite (b) at various temperatures. Regions 1 and 2 in figure (b) are featured by different slopes of the dependencies.

\section{Conclusions}

Charge transport in low-density polyethylene (LDPE) filled with nanoparticles of alumina $\left(\mathrm{Al}_{2} \mathrm{O}_{3}\right)$ and magnesia $(\mathrm{MgO})$ as well as the unfilled counterpart was investigated by means of conductivity and surface potential decay (SPD) measurements. As compared to the pure polymer case, a remarkable reduction in dc conductivity was found for both LDPE nanocomposites at filler content of $3 \mathrm{wt} \%$. Results of SPD measurements on multilayered samples strongly suggest that (a) charge injection at the air-insulation interface and the transport of injected charges are dominating in decay process; and (b) positive charges are prevailing in LDPE. Based on these, mobility of holes in the considered materials has been deduced by using measured data on single-layered samples. The reduced mobility of charge carriers and the increased trap depth obtained in nanocomposites are closely correlated with the weakened charge transport, and hence, decreased dc conductivity of the nanofilled materials. Additionally, by using the measured current density and the calculated charge mobility, lower activation energies were obtained for nanocomposites compared to unfilled LDPE, indicating weaker temperature dependencies of the studied properties in nanofilled dielectrics. The field dependency of the current density derived from SPD measurements was analyzed, showing that the conduction mechanisms in studied materials are strongly affected by presence of nanofillers and temperature. The obtained experimental results are further utilized for computer simulations of charge transport in LDPE and its nanocomposites which are presented in the second part of the work.

Supplementary Materials: The supplementary materials can be found at www.mdpi.com/2073-4360/8/3/87/s1.

Acknowledgments: The financial support provided by Chalmers Area of Advance in Energy and Swedish Foundation for Strategic Research is gratefully acknowledged.

Author Contributions: Anh T. Hoang conducted measurements, performed analysis and systematization of the results, prepared the manuscript. Yuriy V. Serdyuk contributed to the analysis and interpretation of the experimental data as well as to the preparation of the manuscript. Stanislaw M. Gubanski coordinated the work, supported the interpretation of the results and contributed to the preparation of the manuscript. Love Pallon and Dongming Liu manufactured materials' samples for testing, while Ulf W. Gedde provided support in materials' sample fabrication.

Conflicts of Interest: The authors declare no conflict of interest.

\section{References and Notes}

1. Hanley, T.L.; Burford, R.P.; Fleming, R.J.; Barber, K.W. A general review of polymeric insulation for use in HVDC cables. IEEE Electr. Insul. Mag. 2003, 19, 13-24.

2. Reddy, C.C.; Ramu, T.S. On the computation of electric field and temperature distribution in HVDC cable insulation. IEEE Trans. Dielectr. Electr. Insul. 2006, 13, 1236-1244. [CrossRef] 
3. Dissado, L.A.; Mazzanti, G.; Montanari, G.C. The role of trapped space charges in the electrical aging of insulating materials. IEEE Trans. Dielectr. Electr. Insul. 1997, 4, 496-506. [CrossRef]

4. Tanaka, T.; Imai, T. Advances in nanodielectric materials over the past 50 years. IEEE Electr. Insul. Mag. 2013, 29, 10-23. [CrossRef]

5. Lewis, T.J. Nanometric dielectrics. IEEE Trans. Dielectr. Electr. Insul. 1994, 1, 812-825. [CrossRef]

6. Roy, M.; Nelson, J.K.; MacCrone, R.K.; Schadler, L.S.; Reed, C.W.; Keefe, R. Polymer nanocomposite dielectrics-the role of the interface. IEEE Trans. Dielectr. Electr. Insul. 2005, 12, 629-643. [CrossRef]

7. Roy, M.; Nelson, J.K.; MacCrone, R.K.; Schadler, L.S. Candidate mechanisms controlling the electrical characteristics of silica/XLPE nanodielectrics. J. Mater. Sci. 2007, 42, 3789-3799. [CrossRef]

8. Fleming, R.J.; Ammala, A.; Lang, S.B.; Casey, P.S. Conductivity and space charge in LDPE containing nanoand micro-sized ZnO particles. IEEE Trans. Dielectr. Electr. Insul. 2008, 15, 118-126. [CrossRef]

9. Murakami, Y.; Nemoto, M.; Okuzumi, S.; Masuda, S.; Nagao, M.; Hozumi, N.; Sekiguchi, Y. DC conduction and electrical breakdown of MgO/LDPE nanocomposite. IEEE Trans. Dielectr. Electr. Insul. 2008, 15, 33-39. [CrossRef]

10. Ishimoto, K.; Kanegae, E.; Ohki, Y.; Tanaka, T.; Sekiguchi, Y.; Murata, Y.; Reddy, C.C. Superiority of dielectric properties of LDPE/MgO nanocomposites over microcomposites. IEEE Trans. Dielectr. Electr. Insul. 2009, 16, 1735-1742. [CrossRef]

11. Tanaka, T.; Kozako, M.; Fuse, N.; Ohki, Y. Proposal of a multi-core model for polymer nanocomposite dielectrics. IEEE Trans. Dielectr. Electr. Insul. 2005, 12, 669-681. [CrossRef]

12. Mizutani, T.; Ieda, M. Carrier transport in high-density polyethylene. J. Phys. D: Appl. Phys. 1979, 12, $291-296$. [CrossRef]

13. Toomer, R.; Lewis, T.J. Charge trapping in corona-charge polyethylene films. J. Phys. D: Appl. Phys. 1980, 13, 1343-1356. [CrossRef]

14. Von Berlepsch, H. Interpretation of surface potential kinetics in HDPE by a trapping model. J. Phys. D: Appl. Phys. 1985, 18, 1155-1170. [CrossRef]

15. Fischer, P.; Röhl, P. Transient currents in oxidized low-density polyethylene. In Mehrphasige Polymersysteme; Fischer, E.W., Horst Müller, F., Kausch, H.H., Eds.; Steinkopff: Dresden, Germany, 1977; Volume 62, pp. 149-153.

16. Liu, D.; Pourrahimi, A.M.; Olsson, R.T.; Hedenqvist, M.S.; Gedde, U.W. Influence of nanoparticle surface treatment on particle dispersion and interfacial adhesion in low-density polyethylene/aluminium oxide nanocomposites. Eur. Polym. J. 2015, 66, 67-77. [CrossRef]

17. Pallon, L.K.H.; Hoang, A.T.; Pourrahimi, A.M.; Hedenqvist, M.S.; Nilsson, F.; Gubanski, S.M.; Gedde, U.W.; Olsson, R.T. The impact of $\mathrm{MgO}$ nanoparticle interface in ultra insulating polyethylene nanocomposites for high voltage DC cables. J. Mater. Chem. A 2016. (under review).

18. IEC Standard 60093. Methods of test for volume resistivity and surface resistivity of solid electrical insulating materials, 1980.

19. Giacometti, J.A.; Oliveira, O.N. Corona charging of polymers. IEEE Trans. Electr. Insul. 1992, 27, $924-943$. [CrossRef]

20. Noras, M.A. Non-Contact Surface Charge/Voltage Measurements: Fieldmeter and Voltmeter Methods; Trek Inc.: Lockport, NY, USA, 2002.

21. Adamec, V.; Calderwood, J.H. On the determination of electrical conductivity in polyethylene. J. Phys. D: Appl. Phys. 1981, 14, 1487-1494. [CrossRef]

22. Le Roy, S.; Teyssedre, G.; Laurent, C.; Montanari, G.C.; Palmieri, F. Description of charge transport in polyethylene using a fluid model with a constant mobility: Fitting model and experiments. J. Phys. D: Appl. Phys. 2006, 39, 1427-1436. [CrossRef]

23. Kumara, S.; Serdyuk, Y.V.; Gubanski, S.M. Surface charge decay on polymeric materials under different neutralization modes in air. IEEE Trans. Dielectr. Electr. Insul. 2011, 18, 1779-1788. [CrossRef]

24. Xu, Z.; Zhang, L.; Chen, G. Decay of electric charge on corona charged polyethylene. J. Phys. D: Appl. Phys. 2007, 40, 7085-7089. [CrossRef]

25. Watson, P.K. The energy distribution of localized states in polystyrene, based on isothermal discharge measurements. J. Phys. D: Appl. Phys. 1990, 23, 1479-1484. [CrossRef]

26. Baum, E.A.; Lewis, T.J.; Toomer, R. Decay of electrical charge on polyethylene films. J. Phys. D: Appl. Phys. 1977, 10, 487-497. [CrossRef] 
27. Sonnonstine, T.J.; Perlman, M.M. Surface-potential decay in insulators with field-dependent mobility and injection efficiency. J. Appl. Phys. 1975, 46, 3975-3981. [CrossRef]

28. Llovera, P.; Molinié, P. New methodology for surface potential decay measurements: Application to study charge injection dynamics on polypropylene films. IEEE Trans. Dielectr. Electr. Insul. 2004, 11, 1049-1056. [CrossRef]

29. Molinié, P. Measuring and modeling transient insulator response to charging: The contribution of surface potential studies. IEEE Trans. Dielectr. Electr. Insul. 2005, 12, 939-950. [CrossRef]

30. Coelho, R.; Jestin, P.; Levy, L.; Sarrail, D. On the return-voltage buildup in insulating materials. IEEE Trans. Electr. Insul. 1987, 22, 683-690. [CrossRef]

31. Kanegae, E.; Ohki, Y.; Tanaka, T.; Sekiguchi, Y.; Murata, Y.; Reddy, C.C. Space charge behavior in multi-layered dielectrics with LDPE and LDPE/MgO nanocomposites. In Proceedings of the 10th IEEE International Conference on Solid Dielectrics (ICSD), Potsdam, Germany, 4-9 July 2010; pp. 1-4.

32. Chen, G.; Tay, T.Y.G.; Davies, A.E.; Tanaka, Y.; Takada, T. Electrodes and charge injection in low-density polyethylene using the pulsed electroacoustic technique. IEEE Trans. Dielectr. Electr. Insul. 2001, 8, 867-873. [CrossRef]

33. Ieda, M.; Sawa, G.; Shinohara, U. A decay process of surface electric charges across polyethylene film. Jpn. J. Appl. Phys. 1967, 6, 793-794. [CrossRef]

34. Perlman, M.M.; Sonnonstine, T.J.; St.Pierre, J.A. Drift mobility determinations using surface potential decay in insulators. J. Appl. Phys. 1976, 47, 5016-5021. [CrossRef]

35. Wintle, H.J. Decay of static electrification by conduction processes in polyethylene. J. Appl. Phys. 1970, 41, 4004-4007. [CrossRef]

36. Pelissou, S.; St-Onge, H.; Wertheimer, M.R. Electrical conduction of polyethylene below and above its melting point. IEEE Trans. Electr. Insul. 1988, 23, 325-333. [CrossRef]

37. Lewis, T.J. Charge transport in polyethylene nano dielectrics. IEEE Trans. Dielectr. Electr. Insul. 2014, 21, 497-502. [CrossRef]

38. Lewis, T.J.; Llewellyn, J.P. Electrical conduction in polyethylene: The role of positive charge and the formation of positive packets. J. Appl. Phys. 2013, 113, 223705. [CrossRef]

39. Raju, G.G. Chapter 7-Field Enhanced Conduction. Dielectrics in Electric Fields; Marcel Dekker: New York, NY, USA, 2003.

40. Mizutani, T.; Suzuoki, Y.; Ieda, M. Thermally stimulated currents in polyethylene and ethylene-vinyl-acetate copolymers. J. Appl. Phys. 1977, 48, 2408-2413. [CrossRef]

41. Ishimoto, K.; Tanaka, T.; Ohki, Y.; Sekiguchi, Y.; Murata, Y. Thermally stimulated current in low-density polyethylene $/ \mathrm{MgO}$ nanocomposite. On the mechanism of its superior dielectric properties. Electr. Eng. Jpn. 2011, 176, 1-7. [CrossRef]

42. Mark, P.; Helfrich, W. Space-charge-limited currents in organic crystals. J. Appl. Phys. 1962, 33, $205-215$. [CrossRef]

43. Mott, N.F.; Gurney, R.W. Electronic Processes in Ionic Crystals; Clarendon Press: Oxford, England, 1948.

44. Boudou, L.; Guastavino, J. Influence of temperature on low-density polyethylene films through conduction measurement. J. Phys. D: Appl. Phys. 2002, 35, 1555-1561. [CrossRef]

(C) 2016 by the authors; licensee MDPI, Basel, Switzerland. This article is an open access article distributed under the terms and conditions of the Creative Commons by Attribution (CC-BY) license (http://creativecommons.org/licenses/by/4.0/). 